\title{
Povidone- Iodine versus Bleomycin Pleurodesis for Malignant Effusion in Bronchogenic Cancer Guided by Thoracic Echography
}

\author{
Hamdy D. Elayouty*, Tarek M Hassan and Zain A. Alhadad
}

Department of Cardiothoracic Surgery, Department of Radiology, Faculty of Medicine, Suez Canal University, Ismaelia, Egypt

\begin{abstract}
Objectives: This study was designed to compare effectiveness of intra-pleural instillation of Bleomycin with instillation of Povidone-iodine for control of malignant pleural effusion among patients with non-small cell lung cancer, guided by results of thoracic Echography.

Methods: Fifty one patients had the possibility of full lung expansion. Drainage of the effusion was followed by instillation of bleomycin or povidone- iodine through the thoracostomy tube. Four weeks after discharge, thoracic echography was performed and repeated 4 weeks later. Follow-up ranged between 4-32 months (mean: $21 \pm 3.5$ months)

Results: We received 79 patients with malignant pleural effusion as stage IV non-small cell lung cancer during the last four years. Seventeen patients had centrally-located tumors with persistent lung atelectasis. Intrapleural injection of streptokinase to breakdown intra-pleural fibrinous adhesions was carried out in 9 cases; and was successful in 6 cases $66 \%$ (6/9). Finally, 54 patients had an evidence of possible lung expansion but three died before pleurodesis. Thus, 51 patients received intra-pleural instillation of bleomycin or povidone-iodine in a randomized prospective comparative study. Among bleomycin group $(n=26)$, echography showed excellent pleurodesis $(n=21)$, effective pleurodesis $(n=2)$ with one or two areas of free mobility and one area of fluid component, weak pleurodesis (no. $=3$ ) with three areas of free lung movement (lung sliding sign) and areas of fluid component. Among povidone-iodine group $(n=25)$ excellent pleurodesis $(n o .=20)$, effective $(n=2)$ and weak pleurodesis $(n=3)$. The six cases with weak pleurodisis in both groups were those who had streptokinase before pleurodesis. Complications and hospital stay were comparable for both groups. Chest X-ray proved recurrence of effusion in the six cases with weak pleurodesis after symptom-free intervals that varied between 4 and 6 weeks among these 6 patients.
\end{abstract}

Conclusions: Both bleomycin and povidone-iodine produced comparable excellent and effective pleurodesis among patients with malignant pleural effusion. The cost is much lower with povidone-iodine.

Keywords: Malignant pleural effusion; Povidone-iodine; Bleomycin; Pleurodesis; Echography; Streptokinase

\section{Introduction}

Malignancy is the major cause of both exudative pleural effusions and massive recurrent pleural effusions [1]. The most common causes of malignant pleural effusions are carcinoma of the lung in men and carcinoma of the breast in women. Our patients had stage IV bronchogenic carcinoma. Intrapleural instillation of chemotherapeutic agents was performed to destroy local tumor implants and induce pleurodesis. Instillation of bleomycin is a well- established technique but unfortunately it is expensive and associated with serious side effects [2]. We usually use 3 to 4 ampoules of bleomycin according to body weight, each one costs 75 dollars. Povidone iodine costs less than 20 dollars for each patient.

We proposed that we may be able to replace bleomycin by the easily-available, less expensive and the less- toxic povidone-iodine for pleurodesis among patients with malignant pleural effusion in the course of bronchoginic carcinoma. This prospective randomized study was designed to compare the effectiveness of $5 \%$ povidone-iodine in the management of malignant pleural effusion with that of bleomycin assessed with thoracic echography.

\section{Methods}

Fifty one patients were included in this study. After thoracocentesis and proved possibility of full lung expansion, small-sized chest tube was inserted to achieve two goals: $1^{\text {st }}$ to achieve complete drainage of pleural effusion and subsequent full lung expansion, $2^{\text {nd }}$ to inject streptokinase into the pleural cavity if lung expansion was locally impeded. Intrapleural injection of streptokinase was successfully performed and followed by full lung expansion in 6 cases out of nine $66 \%$ (6/9). Streptokinase, $250,000 \mathrm{U}$ in $100 \mathrm{~mL}$ of $0.9 \%$ saline solution, was instilled daily into the chest tube, and the tube was clamped for 4 hours followed by suction. This treatment was continued daily for 3 to 9 days until resolution was demonstrated by chest radiograms or computed chest tomography. Patients with recent operation, recent biopsy, recent trauma or history of severe allergy were excluded. We did not use video-assisted thoracoscopy (VATS) to free the pleural cavity, as most of these patients could not tolerate general anesthesia.

Patients were randomly distributed between bleomycin group and povidone-iodine group. If the number allocated to the patient entering

${ }^{*}$ Corresponding author: Dr. Hamdy D. Elayouty, Department of Cardiothoracic Surgery, Suez Canal University Hospitals, Ismailia, Egypt, Tel: 0020137271234/002-0132720646; Fax: 0967-5326622; E-mail: h.dosoky@yahoo.com

Received April 21, 2012; Accepted June 22, 2012; Published June 25, 2012

Citation: Elayouty HD, Hassan TM, Alhadad ZA (2012) Povidone- lodine versus Bleomycin Pleurodesis for Malignant Effusion in Bronchogenic Cancer Guided by Thoracic Echography. J Cancer Sci Ther 4: 182-184. doi:10.4172/19485956.1000137

Copyright: (c) 2012 Elayouty HD, et al. This is an open-access article distributed under the terms of the Creative Commons Attribution License, which permits unrestricted use, distribution, and reproduction in any medium, provided the original author and source are credited. 
the trial was odd, the patient was allocated to bleomycin group; if the number was even, the patient was allocated to povidone group.

This was followed by intra-pleural injection of bleomycin $(60 \mathrm{U}$ in $100 \mathrm{ml}$ normal saline) or $5 \%$ povidone iodine through the thoracostomy tube. Lidocaines (xylocaine) $1 \% 20-30 \mathrm{ml}$ were added to reduce pain. We usually use 3 to 4 ampoules of bleomycin according to body weight; each one costs 75 dollars in our countries. Povidone- iodine costs less than 20 dollars for each patient. Narcotic analgesics were prescribed to control post-operative pain. After instillation of bleomycin or povidone iodine, the tube was occluded for sex hours. The tube was released for a short time after this period of occlusion. A little amount of fluid or air was usually drained before removal of the tube. Each patient was informed about the program of follow up before his discharge.

Four weeks after discharge, thoracic echography was performed and repeated after additional 4 weeks. During thoracic echography, the patient was sitting with arms elevated and the hands positioned behind the neck. The probe was positioned in the intercostal space at 9 different predefined points, 2 on the mid-clavicular line (II and IV intercostal spaces), 3 on the mid-axillary line (II, IV and VI intercostal spaces) and 4 posteriorly on the midline between the spine and the medial border of the scapula (II, V, VII and IX inter-costal spaces). We used. 3.5 $\mathrm{MHz}$ linear array transducer for all cases. Follow-up ranged between: 4-32 months (mean: 21.5 months). Patients with recurrence refused repeating the procedure of chest tube and pleurodesis except one for whom a thoracostomy tube was inserted. The tube drained 200 to 300 $\mathrm{ml}$ of exudative effusion and the patient had persistent hypotension until he died on the $7^{\text {th }}$ day after insertion of the tube. The remaining five patients had repeated thoracocentesis.

\section{Statistical Analysis}

We used the mean and the average the bivariate analysis was used to compare results among the two groups. The procedure of pleurodesis aim at improving patient's symptoms rather than the survival rate. Survival curves were difficult to draw because of the small sample size.

\section{Results}

We received 74 patients with malignant pleural effusion as an advanced stage of non-small cell lung cancer during the period from March 2006 to April 2010 (Table 1). Seventeen patients were excluded due to persistent lung collapse (centrally- located masses occluding the bronchial tree). Fifty four patients had an evidence of possible lung expansion; six of them had successful intrapleural injection of streptokinase. Of the 9 patients who had this therapeutic trial $66 \%$ (6/9). Three patients: were lost before pleurodesis: two died because of extensive metastases and one died after an extensive myocardial infarction. Thus, fifty one had pleurodesis and completed the follow up. Four weeks after pleurodesis, they had echography that was repeated 4 weeks later (Table 2). Thus, patients who completed the study were 51: thirty four males and 17 females and their mean age were $46+$ 3.6 years. Patients were randomized to bleomycin pleurodesis or $5 \%$ povidone iodine pleurodesis. Among bleomycin group (26 patients), echography showed excellent pleurodesis in 21 patients without any areas of free lung movement or any fluid component in the examined nine areas, effective pleurodesis in 2 cases with one or two areas of free mobility and one area of fluid component, weak pleurodesis in three cases with three areas of free lung movement and areas of fluid component. bleomycin resulted in excellent and effective pleurodesis in $85 \%(23 / 26)$ and weak pleurodesis and recurrence in $15 \%(3 / 26)$. The povidone-iodine group ( 25 cases), 20 had excellent and 2 with effective and 3 had weak pleurodesis. We noticed that the six patients who had previous intrapleural injection of streptokinase several days before instillation of bleomycin or povidone iodinne (3 to 5 days) had weak pleurodesis and recurrence of effusion. Symptom-free interval ranged between 4 and 6 weeks among those 6 patients. Postoperative complications included low grade fever, transient leucopenia, and mild to moderately severe pain (Table 3 ). Patients who had excellent and effective pleurodesis continued symptom-free until the end of the follow up period.

\section{Discussion}

The most common causes of malignant pleural effusions are carcinoma of the lung in men and carcinoma of the breast in women. Malignant involvement of the pleura is the most frequent cause of a grossly bloody pleural effusion [3]. Thoracentesis is a simple procedure that can effectively relieve the respiratory symptoms. Unfortunately, malignant pleural effusions recur within 1 month, with an average recurrence time of 4.2 days. Repeated thoracentesis, especially with high- protein exudates, can lead to hypo-proteineamia that will lead to more rapid re-accumulation of pleural fluid [4]. Therefore, thoracentesis should be used to: evaluate the initial effusion by determining its cause and tendency to re-accumulation and the ability of the underlying lung to re-expand and relieve the respiratory symptoms [5]. During insertion of the thoracostomy tube, introduction of the little finger through the hole can help assess the pleural cavity and presence of weak fibrenous adhesions may indicate intrapleural instillation of streptokinase. This was the situation in 9 of this series who had instillation of streptokinase; it was successful in only 6 cases. To prevent re-accumulation of pleural fluid we should try pleurodesis. Pleurodesis is the creation of fibrous adhesions between the visceral and parietal layers of the pleura, thus obliterating the pleural cavity [3]. Intrapleural instillation of a chemical irritant (chemical pleurodesis) is an effective way to prevent recurrence of pleural effusion [6]. We are comparing two of such substances: Bleomycin and $5 \%$ povidone-iodine.

\begin{tabular}{|l|l|}
\hline $\begin{array}{l}\text { Total number of patients with malignant effusion (stage IV } \\
\text { bronchogenic carcinoma) }\end{array}$ & 74 \\
\hline Patients with centrally-located masses with lung atelectasis & 17 \\
\hline Patients who received streptokinase to achieve lung expansion & 9 \\
\hline Patients who received streptokinase and achieved lung expansion & 6 \\
\hline Patients who died due to metastases or myocardial infarction & 3 \\
\hline Total number of patients with full lung expansion: & 51 \\
\hline Males/ females & $34 / 17$ \\
\hline Mean age & $46 \pm 3.6$ years \\
\hline Patients who had pleurodesis and completed the follow up: & 51 \\
\hline - Patients with bleomycin pleurodesis & 26 \\
\hline - Patients with iodine pleurodesis & 25 \\
\hline
\end{tabular}

Table 1: Patient characteristics.

\begin{tabular}{|l|c|c|c|}
\hline Results of pleurodesis & Bleomycin group & Povidone iodine- group & P value \\
\hline Excellent & $21(76 \%)$ & $20(80 \%)$ & 0.072 \\
\hline Effective & $2(7 \%)$ & $2(7 \%)$ & 0.093 \\
\hline $\begin{array}{l}\text { Weak and } \\
\text { consequently recurred }\end{array}$ & $3(11 \%)$ & $3(11 \%)$ & 0.324 \\
\hline Total & 26 & 25 & 0.062 \\
\hline
\end{tabular}

Table 2: Results of Thoracic Echography after pleurodesis.

\begin{tabular}{|l|c|c|c|}
\hline Complication & Bleomycin group & lodine group & P value \\
\hline Low grade fever & $9(34 \%)$ & $8(32 \%)$ & 0.198 \\
\hline Transient leucopenia & $4(15 \%)$ & $1(4 \%)$ & 0.273 \\
\hline Mild to moderately severe pain & $14(53 \%)$ & $17(68 \%)$ & 0.052 \\
\hline Recurrent effusion & $3(11 \%)$ & $3(11 \%)$ & 0.437 \\
\hline
\end{tabular}

Table 3: Complications after pleurodesis. 
Citation: Elayouty HD, Hassan TM, Alhadad ZA (2012) Povidone- lodine versus Bleomycin Pleurodesis for Malignant Effusion in Bronchogenic Cancer Guided by Thoracic Echography. J Cancer Sci Ther 4: 182-184. doi:10.4172/1948-5956.1000137

Thoracic echography detects the sign of 'pleural sliding', produced by movement of the visceral pleura on the parietal pleura. This sign is absent when pleurodesis is present. According to Lichtenstein [7] guidelines, echographic finding can be defined as follows: pleurodesis (PD) when the pleural sliding was absent and the lung was seen after the pleural line (the 'comet tails' sign), pneumothorax (PX) when pleural sliding was absent and no lung was detected after the pleural line (the 'stratosphere sign'), fluid (FL) when a liquid component was detected $[8,9]$. Pleurodesis was defined excellent when pleurodesis was confirmed in all the 9 considered points, effective when it was confirmed in more than 6 points, poor when it was confirmed in 6 points or less [10]. Lardenios et al. [11] advised not to prescribe nonsteroidal anti-inflammatory drugs after induction of pluerodesis. Any pleural airspace or fluid collection in the early post-operative period can be dealt with aggressively by increasing suction pressure or repositioning the drain to allow full lung expansion, because pleural apposition is the key to effective pleurodesis. Similarly, avoiding air leak into the pleural space during chest drain removal is also important. Effectiveness of pleurodesis after instillation of streptokinase can be due to a variable amount of fibrinous adhesions or the use of streptokinase to dissolve these adhesions and subsequently interfere with the process of pleurodesis. This clinical observation may indicate further studies.

Streptokinase is a sterile purified preparation of a bacterial protein elaborated by group C (beta) -hemolytic streptococci. It is supplied as a lyophilized white powder containing $25 \mathrm{mg}$ cross-linked gelatin polypeptides, $25 \mathrm{mg}$ sodium L-glutamate, sodium hydroxide to adjust $\mathrm{pH}$, and $100 \mathrm{mg}$ Albumin (Human) per vial or infusion bottle as stabilizers. The preparation contains no preservatives and is intended for intravenous or intracoronary administration.

Intrapleural fibrinolytic agents, streptokinase and urokinase, are safe, cost-effective means of facilitating complete chest tube drainage of exudative pleural effusions or empyema. Thus, bleomycin resulted in excellent and effective pleurodesis in 23/26 (89\%) and weak pleurodesis and recurrence in $3 / 26$ (11\%). Povidone iodine lead to excellent and effective pleurodesis in $22 / 25(88 \%)$ and weak pleurodesis in 3 cases $3 / 25(12 \%)$. povidone-iodine is available, cost effective and can be repeated if necessary. Postoperative complications were comparable in both groups. Patients who had intra-pleural injection of streptokinase had weak pleurodesis and recurrence.

\section{Conclusions}

Both bleomycin and povidone iodine produced comparable excellent and effective pleurodesis among patients with malignant pleural effusion (stage IV bronchogenic carcinoma).

\section{Acknowlegement}

Thanks to Prof. Alaa Eldeen Sad who supplied us with the laboratory results of pleural fluid cytology.

\section{References}

1. Robinson LA, Fleming WH, Galbraith TA (1993) Intrapleural doxycycline control of malignant pleural effusions. Ann Thorac Surg 55: 1115-1122.

2. Siegel RD, Schiffman FJ (1990) Systemic toxicity following intracavitary administration of bleomycin. Chest 98: 507.

3. Shields TW (2009) Primary tumors of the pleura. General Thoracic Surgery, $7^{\text {th }}$ (Edn), Philadelphia, Lea \& Fwbiger 650-656.

4. Collins TR, Sahn SA (1987) Thoracocentesis. Clinical value, complications, technical problems, and patient experience. Chest 91: 817-822.

5. (1997) Pretreatment evaluation of non-small-cell lung cancer. The American Thoracic Society and The European Respiratory Society. Am J Respir Crit Care Med 156: 320-332.

6. Reshad K, Inui K, Takeuchi Y, Takahashi Y, Hitomi S (1985) Treatment of malignant pleural effusion. Chest 88: 393-397.

7. Lichtenstein D (2003) Échographie pleuro-pulmonaire Lung ultrasound Réanimation 12: 19-29.

8. Thurter R, Cimochowski G, Feun L, Ruchdeschel J (1989) Malignant pleura effusions. Contemp Surg 35: 79.

9. Beauchamp G, Ouellette D (2002) Spontaneous pneumothorax and pneumomediastinum. In: Pearson FG, Cooper JD, Deslauriers J, Ginsberg RJ, Hiebert CA, Patterson GA, Urschel HC (Eds), Thoracic Surgery. ( $2^{\text {nd }}$ Edn), Philadelphia: Churchill Livingstone 1195-1213.

10. Smit HJ, Wienk MA, Schreurs AJ, Schramel FM, Postmus PE (2000) Do bullae indicate a predisposition to recurrent pneumothorax? Br J Radiol 73: 356-359.

11. Lardinois D, Vogt P, Yang L, Hegyi I, Baslam M, et al. (2004) Non-steroida anti-inflammatory drugs decrease the quality of pleurodesis after mechanical pleural abrasion. Eur J Cardiothorac Surg 25: 865-871. 